\title{
CATTLE (BOS TAURUS) ENDOMETRIUM MORPHOLOGY ON THE SEVENTH DAY OF THE ESTROUS CYCLE
}

\author{
*Olga Ponomarjova ${ }^{1}$, Ilga Sematovica ${ }^{1}$, Inga Piginka-Vjaceslavova ${ }^{2}$, Aida Vanaga ${ }^{1}$ \\ ${ }^{1}$ Latvia University of Life Sciences and Technologies, Latvia \\ ${ }^{2}$ Institute of Food Safety Health and Environment BIOR, Latvia \\ *Corresponding author's email: olga.ponomarjova@llu.lv
}

\begin{abstract}
The aim of our study was to describe the histopathological and cytological characteristic of the cow endometrium on the seventh day of the estrous cycle. In this study, 11 different breeds' dairy cows ( $78.18 \pm 37.46$ months old, in 3.6 \pm 2.17 lactation, the mean body condition score $3.4 \pm 0.72$ (5 points scale)) from Research and Study farm 'Vecauce' were selected. All cows were more than 210 days postpartum. Overall health and reproductive tract examination was performed, progesterone (P4) and estradiol (E2) concentration in blood serum were established and the biopsy

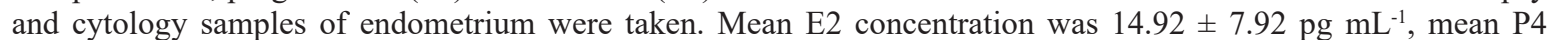
concentration was $13.64 \pm 9.44 \mathrm{nmol} \mathrm{L}^{-1}$. The mean percentage in the cytology slides was established: epithelial cells $89 \pm 9 \%$, polimorphonuclear leukocytes (PMN) $6 \pm 5 \%$. Cytological subclinical endometritis (SE) was confirmed in 5 cows. Histopathological findings (out of 22 samples): endometrium stromal edema in 14, hemosiderin and hemosiderophages in 8 , supranuclear vacuolization in 12 , pseudodecidual reaction in 12 samples. No subnuclear vacuolization and mitosis in the glandular epithelium were detected. Histopathological examination did not reveal SE. Morphology between the uterine horns with and without corpus luteum (CL) and between cows with serum P4 level higher than $15 \mathrm{nmol} \mathrm{L}^{-1}$ and lower than $15 \mathrm{nmol} \mathrm{L}^{-1}$ were not statistically different $(\mathrm{p}>0.05)$. In conclusion, histopatological examination is more reliable diagnostic method for SE. Future investigation should be performed to establish cut-off values for the diagnosis of SE in cows more than 210 days postpartum.
\end{abstract}

Key words: cattle endometrium, cytology, histopathogy, estrous cycle.

\section{Introduction}

According to Agricultural Data Centre Republic of Latvia, the number of dairy cows in Latvia since 2010-2015 decreased by $0.1 \%$, but since 2015-2020 it decreased by $16.6 \%$. However, productivity has increased by $31 \%$ in the last 10 years. An increasingly important issue is not only the reproductive health of dairy cows in general, but also the reproduction of high-yielding and genetically valuable cows. For this reason, assisted reproduction techniques are being introduced in Latvia within last years - various synchronization protocols, use of sex-sorted sperm, multiple ovulation (MO) and embryo transfer (ET), oocyte aspiration and fertilization in vitro.

On the seventh day of the estrous cycle, the embryo enters in to the uterine horn and contacts to the endometrium. In the process of MO and ET in cattle the embryos are collected and transfered to the recipients uterus horn ipsilateral to CL or could be cryopreserved. There are many factors which affect successful ET process, such as the health of the endometrium in donors and recipients, quality of the embryos, fresh or frozen embryo transfer, serum P4 concentration during the luteal phase of the reproductive cycle and others. The common reasons of unsuccessful ET process were described in previous studies, such as the subclinical endometritis (SE) and endometritis and low circulating P4 concentration (JimenezKrassel et al., 2009; Pascottini et al., 2017; EstradaCortés et al., 2019). Histopathological examination of the endometrium biopsy samples and exfoliative cytological examination of the endometrium are the gold standard for evaluation of the uterine condition (Benbia et al., 2013). For this, the seventh day of the estrous cycle is the area of the interest in our study.

The aim or our study was to describe the histopathological and cytological characteristic of the cow endometrium on the seventh day of the estrous cycle in relation to steroid hormones (E2 and P4). The objectives of the study were to detect and evaluate the morphological findings in the cow endometrium between uterine horns depending on the presence of the CL in the ovary and serum P4 level on the seventh day of the oestrus cycle.

\section{Materials and Methods}

Eleven Research and Study farm 'Vecauce' dairy cows (eight Holstein and three Latvian Brown cows) were selected for this study during the period from January 2019 until January 2020. Cows were $78.2 \pm 37.46$ months old (min. 37, max. 158 months), they were in $3.6 \pm 2.17$ lactation (min. 1.0, max. 7.0 lactation) and the mean body condition score (BCS) was $3.4 \pm 0.72$ ( 5 points scale). Cows were more than 210 days postpartum. Cows were synchronized with Ovarelin (Gonadorelin, Ceva Sante Animale, France) injections $50 \mu \mathrm{g} \mathrm{ml}^{-1} 2 \mathrm{ml}$ i.m. (0, 10 day) and Enzaprost (Dinoprost, Ceva Sante Animale, France) $5 \mathrm{mg} \mathrm{ml}^{-1} 5 \mathrm{ml}$ i.m. (7, 8 day).

Overall health and reproductive tract examination was performed on the seventh day of the estrous cycle. Uterus, uterine horns and ovarian structures (CL and follicles) were assessed by rectal palpation and transrectal reproductive ultrasonography (Easi-Scan, 
BCF Technology). Blood samples were collected from tail vein to establish $\mathrm{P} 4$ and E2 concentration. Analyses of P4 and E2 were carried out in the accredited laboratory of the Institute of Food Safety, Animal Health and Environment 'BIOR', Latvia (No. LVS EN ISO/IEC 17025:2017). Before endometrial cytology and biopsy samples were taken using cytobrushes (Mekalasi, SAXO, Finland), epidural anesthesia was provided using Procamidor $20 \mathrm{mg}$ $\mathrm{ml}^{-1}$ (Procaini hydrochloridum, Richter Pharma AG, Austria) 2.0-4.0 ml. Endometrial cytology samples were obtained under rectal guidance. The cytobrush, placed in a stainless steel tube, was inserted into the uterine lumen through the uterine cervix. Then the brush was released in the uterine lumen and rotated against the uterine body dorsal wall. Slides for cytological examination were prepared by rolling the cytobrush onto a clean glass slide. Cytology slides were stained with Diff-Quick stain (Sysmex, Japan). Two slides from each cow were prepared for examination. Two hundred cells on each slide were differentiated (light microscope Nikon Eclipse 80i, $400 \times$ magnification) and the percentage of PMN was assessed (Melcher, Prunner, \& Drillich, 2014). The threshold level of PMN for diagnosis of SE was set at 5\% (Egberts et al., 2016). A total of 22 slides was investigated by doctoral student in the laboratory of Latvia University of Life Sciences and Technologies Small Animal Veterinary clinic in collaboration with experience laboratory staff.

Endometrial biopsy samples using the endometrial biopsy instrument (Denmark, 'Kruuse') were obtained. The biopsy instrument was introduced into the uterine lumen under rectal guidance, and biopsies were taken from the ventral surface of the right and left uterine horn dorsal wall.

The total number of histopathological samples was 22 samples. The samples were prepared for further histopathological examination: fixed in $10 \%$ neutral formalin and stored for 24 hours in room temperature. The Leica TP 1020 tissue processor for dehydration and fat removal was used. Then the samples were embedded in the paraffin blocks. The samples were sectioned at $5-\mu \mathrm{m}$ thickness and were put on the slides. The drying process was performed $+58{ }^{\circ} \mathrm{C}$ for $20 \mathrm{~min}$ in Binder 140KB 53 thermostat. Samples were stained with haematoxylin and eosin $(\mathrm{H} / \mathrm{E})$ and light microscope Zeiss was used for evaluation of endometrium morphology. Histopathological examination was performed at the Institute of Food Safety, Animal Health and Environment 'BIOR', Latvia.

In each sample the following histopathological characteristic principles were assessed: 1) size of the glandular epithelium (3 point system: 1- small with strong eosinophil cytoplasm and small amount of cytoplasm; 2- medium with light eosinophil cytoplasm and medium amount of cytoplasm; 3large with very light cytoplasm and large amount of cytoplasm); 2) vacuolization of glandular epithelium cytoplasm (presence of supranuclear or subnuclear vacuoles); 3) mitosis in the glandular epithelium; 4) pseudodecidual reaction in glandular epithelium; 5) secret of glandular epithelium in the glands lumen; 6) endometrium stromal edema; 7) hemosiderin in the endometrium; 8) inflammatory cells in endometrium in the glands area.

Morphological parameters of endometrium were compared between uterine horns with CL and without $\mathrm{CL}$ presence in ovaries; between cows with high serum P4 level ( $\left.>15 \mathrm{nmol} \mathrm{L}^{-1}\right)$ and low serum P4 level $\left(<15 \mathrm{nmol} \mathrm{L}^{-1}\right)$ (Pascottini et al., 2016; Benbia et al., 2017).

Data are expressed as the mean $\pm \mathrm{SD}$, percentage and independent samples t-tests were performed for statistical analysis considering the significance level of $p<0.05$ using IBM SPSS Statistics 21 software.

\section{Results and Discussion}

All 11 cows selected for this study were clinically healthy. Examination of reproductive tract revealed that 10 cows had at least one CL and one follicle in the ovaries and one cow had not CL at all, only few follicles.

Mean E2 concentration was $14.92 \pm 7.92$ pg $\mathrm{mL}^{-1}$, (min. 9, $\max 31.73$ ). Cows without $\mathrm{CL}$ in the ovaries had higher E2 concentration in blood serum (31.73 $\mathrm{pg} \mathrm{mL}^{-1}$,) than cows with CL presence in the ovaries (13.24 $\pm 5.78 \mathrm{pg} \mathrm{mL}^{-1}$, min. 9, $\left.\max .25 .84\right)$.

Mean P4 concentration was $13.64 \pm 9.44 \mathrm{nmol} \mathrm{L}^{-1}$ (min 1.05, max. 28.11). Two cows had P4 concentration less than $1.2 \mathrm{nmol} \mathrm{L}^{-1}$. It proves a very low CL functional activity. One cow without CL had low $\mathrm{P} 4$ concentration $\left(4.83 \mathrm{nmol} \mathrm{L}^{-1}\right)$ in blood serum. This can be explained by the effect of the dominant follicle producing E2 during first follicular wave (Muira, 2019).

The mean percentage of epithelial cells (Figure 1a) in the cytology slides was $89 \pm 9 \%$ ( $\min .73, \max .98)$, the mean percentage of the PMN (Figure 1.b.) was $6 \pm 5 \%$ (min. 1, max. 19). Eosinophil leukocytes were detected in two samples $(n=11)$, one and two cells respectively. The lymphocytes were in eight samples, the mean percentage was $4 \pm 5 \%$ (min. 0 , max.15). The monocytes were detected in two samples, one and two cells respectively. In 5 cytology samples the PMN threshold of $5 \%$ was exceeded, 5 cows $(n=11$; mean $6 \pm 5 \%$, min. 1, max 19) have had elevated percentage of PMN and diagnosis of subclinical endometritis (SE) was confirmed. In two samples eosinophils were detected in the slides ( 1 and $2 \%$ ). In the previous study, the prevalence of SE was $12.7 \%$ diagnosed by 


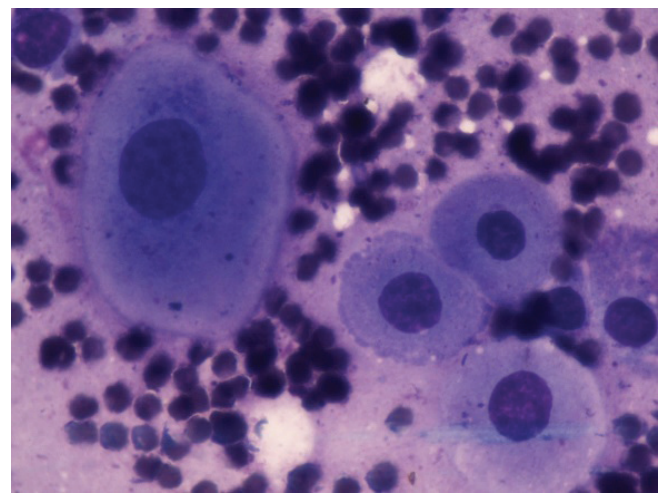

1a. Epithelial cells (arrow), 400× magnification.

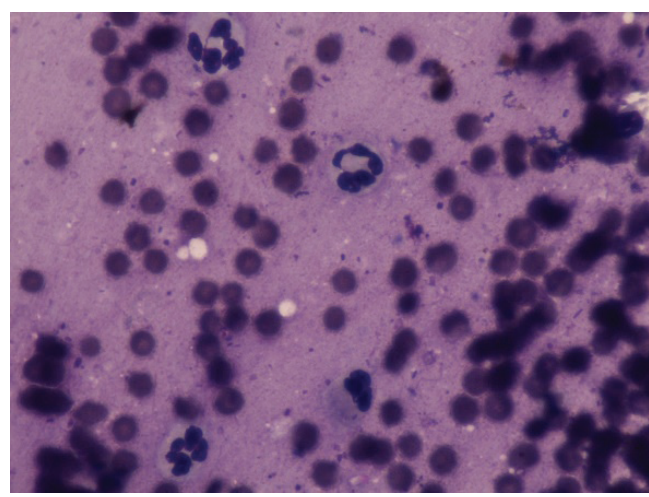

1b. PMN (arrow), 400× magnification.

Figure 1. Exfoliative cytology of cow endometrium on the seventh day of the estrous cycle.

cytological examination, which was not consistent with our study result (Pothmann et al., 2015).

In 22 biopsies samples (11 from the left and 11 from the right uterine horns) performed histopathological examination revealed the following:

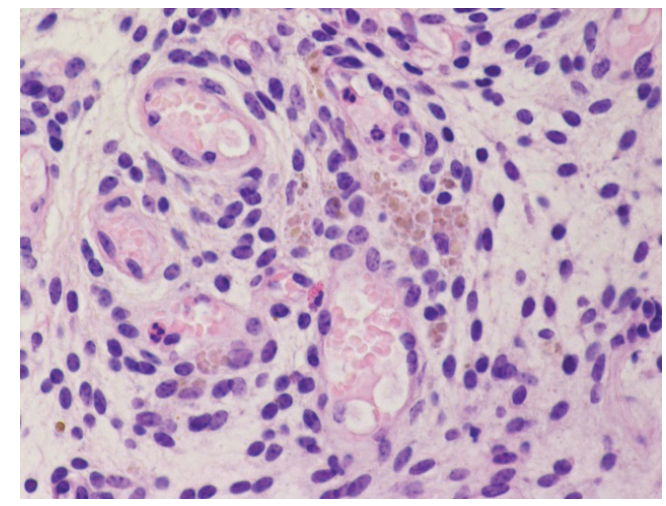

2a. Inflammation cell in endometrium stroma. Red arrow neutrophil leucocyte, black arrow - eosinophil leucocyte, green arrow - hemosiderophage, $600 \times$ magnification.

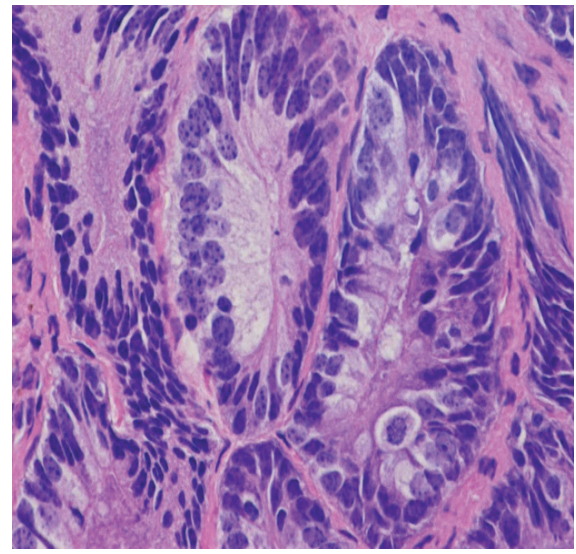

2c. Pseudodecidual reaction. Black arrow - glandular epithelium cell is large, nucleus of cell is large and pale with visible nucleoli. $600 \times$ magnification. endometrium stromal edema (Figure 2b) was in 14 samples, hemosiderin and hemosiderophages in 8 , supranuclear vacuolization (Figure $2 \mathrm{~d}$ ) - in 12 , subnuclear vacuolization in none of samples, pseudodecidual reaction (Figure 2c) - in 6, mitosis

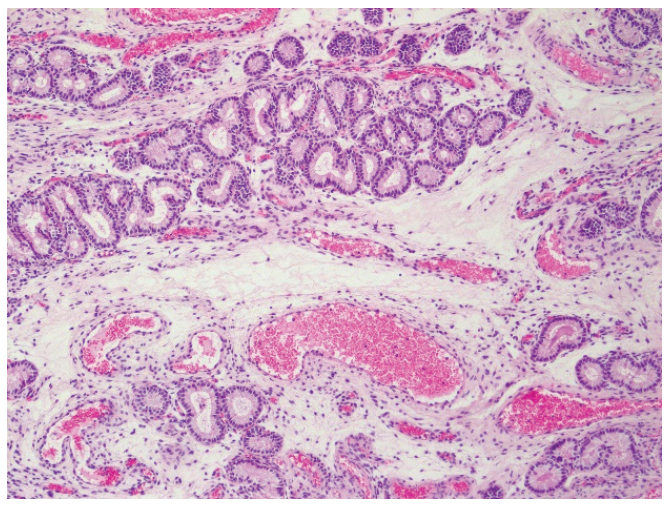

2b. Endometrium edema. Black arrow - fluid in stroma of endomentrium, $600 \times$ magnification.

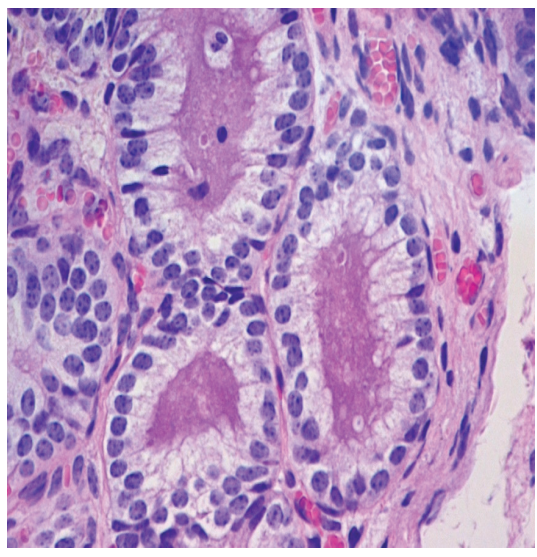

2d. Vacuolization of glandular epithelium cytoplasm. Black arrow - supranuclear vacuoles, red arrow - secret of glandular epithelium in the gland lumen. $600 \times$ magnification.

Figure 2. Histopathology of the cow endometrium on the seventh day of the estrous cycle. 


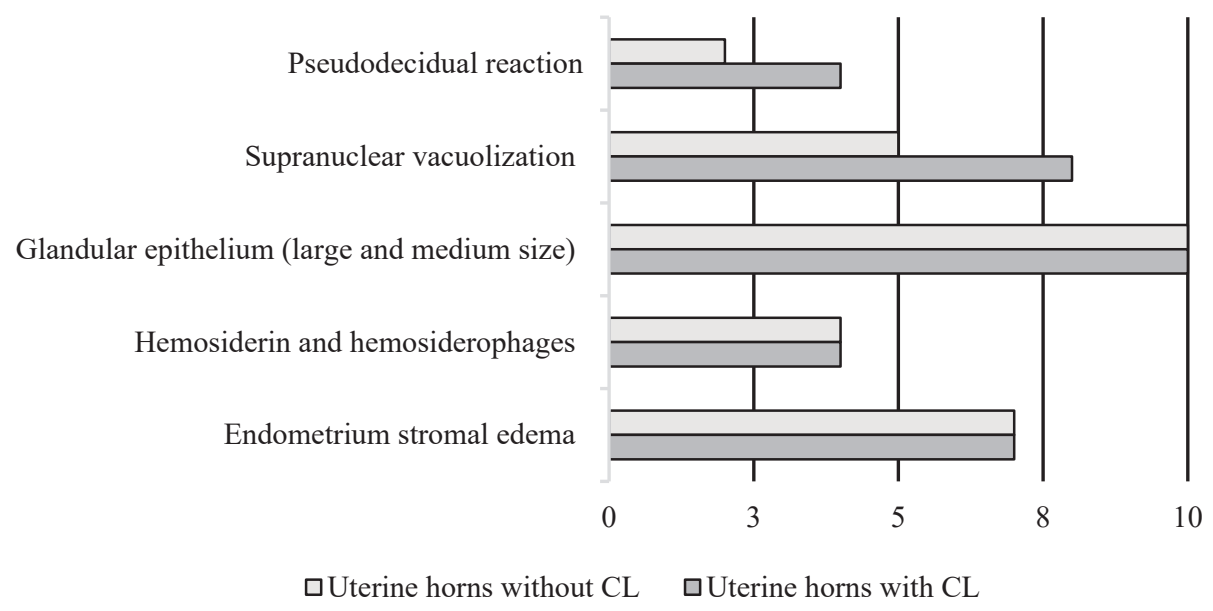

Figure 3. The morphological findings in the endometrium of the uterine horns between the uterine horns with $(n=12)$ and without CL $(n=10)$.

in the glandular epithelium was found in none of samples. In 20 samples, the glandular epithelium was large and medium size, in 2 samples - small size. In luteal phase, glandular epithelium becomes higher and contains large number of secretion vacuoles. Mitosis in the glandular epithelium and endometrium stromal edema characterize follicular phase (Espejel \& Medrano, 2017).

The infiltration of neutrophil leukocytes in the endometrium was not detected in any of samples, the infiltration of eosinophil leukocytes - in 4 samples (Figure 2a). The mean cells count was $0.9 \pm 2.65$ (min.0, max 11 cells). The infiltration of the mast cells was in 7 samples. The mean cells count was $0.82 \pm 0.78$ (min. $0, \max 4)$. Presence of inflammatory cells in the endometrium is still under discussion. Eosinophil leukocytes may be present in the stratum compactum of the endometrium and their number is invariable throughout estrous cycle. The infiltration of neutrophils can be in the endometrium during proestrus, estrus, and metestrus. As swell as mast cells can form clusters (5-10 cells) in the stratum compactum in any stage of the estrous cycle (Espejel \& Medrano, 2017).

Histopathological results show that no one of these cows had SE or endometritis. Characteristic histopathological features of SE are epithelial degeneration and desquamation in the epithelial lamina and of endometritis - focal or diffuse inflammatory cells infiltration of lymphocytes, plasma cells and PMN in lamina propria (Dogan, Sonmez, \& Sagirkaya, 2002).

There was no statistically significant difference in the morphological finding in the endometrium between the uterine horns with CL $(n=12)$ and without CL $(n=10)$ : endometrium stromal edema $\mathrm{p}=0.59$,

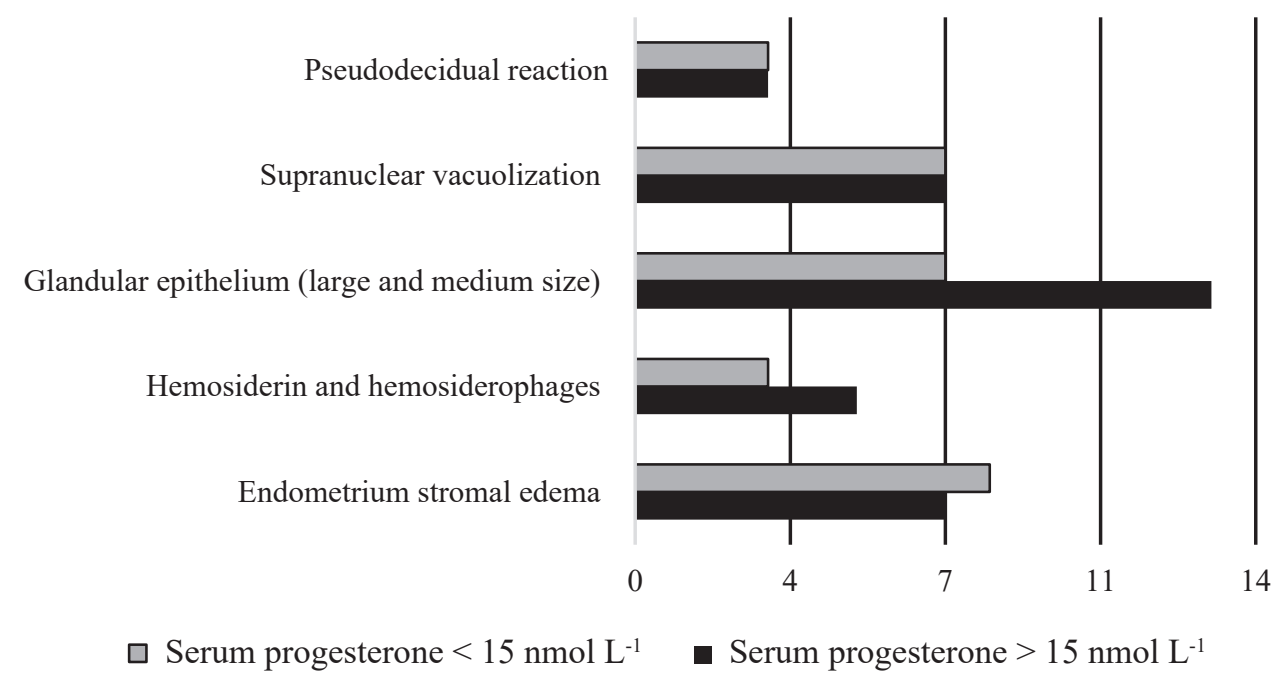

Figure 4. The morphological findings in the endometrium of the uterine horns between cows with serum progesterone level $>15 \mathrm{nmol} \mathrm{L}^{-1}(\mathrm{n}=13)$ and with serum progesterone $<15 \mathrm{nmol} \mathrm{L}^{-1}(\mathrm{n}=10)$. 
hemosiderin and hemosiderophages $\mathrm{p}=0.76$, size of the glandular epithelium $\mathrm{p}=0.34$, supranuclear vacuolization $\mathrm{p}=0.45$, pseudodecidual reaction $\mathrm{p}=0.50 ; \mathrm{p}>0.05$ (Figure 3 ). The recommendation for successful embryo transfer is to place the embryo into the uterine horn with CL in the ipsilateral ovary. In the previous study, differences in gene expression between the endometrium of uterine horns ipsilateral and contralateral to the CL in cattle were defined, but the site of embryo transfer did not affect pregnancy establishment in cattle (Sanchez et al., 2018). Our study showed that morphological finding in the endometrium was similar between uterine horns with and without CL in ovary.

There was no statistically significant difference in the morphological finding in the endometrium of the uterine horns between cows with serum P4 level $>15$ $n \mathrm{nmolL}^{-1}(\mathrm{n}=13)$ and with serum $\mathrm{P} 4<15 \mathrm{nmolL}^{-1}(\mathrm{n}=10)$ : endometrium stromal edema $\mathrm{p}=0.27$, hemosiderin and hemosiderophages $p=0.69$, size of the glandular epithelium $\mathrm{p}=0.08$, supranuclear vacuolization $\mathrm{p}=0.45$, pseudodecidual reaction $\mathrm{p}=0.73 ; \mathrm{p}>0.05$ (Figure 4). In the previous study authors did not define correlation between endometrium morphology and serum P4 level concentration in cattle blood between the 5th and 8th estrous day similar to the results of our study (Wang et al., 2007).

The histopathological examination results did not confirm diagnosis of SE. It could be explained, because of the threshold for the diagnosis of SE is still under discussion and varied between $5 \%$ and $18 \%$, depending on the days postpartum (Wagener, Gabler, \& Drillich, 2017). The cytology has a lower sensitivity to diagnose inflammatory reactions in the endometrium of dairy cows in comparison to histopathology (Pascottini et al., 2016). In the later postpartum period (30-60 days), the threshold for SE was 10\% (Cheong et al, 2011) and 5\% (Gilbert et al., 2005; Madoz et al., 2013). In our study cows were $>210$ days postpartum, so it is possible that it was the reason of SE prevalence in 5 cows $(n=11)$. Some authors considered that cut-off values for the diagnosis were $18 \%$ (Kasimanickam et al., 2004). If cut-off for diagnosis of SE was accepted $18 \%$, in our study one cow had SE $(n=11)$.

\section{Conclusions}

The main morphological findings in the cow endometrium on the seventh day of the estrous cycle were endometrial glands activity and endometrium stromal edema without significant differences between the uterine horns with and without CL in the ipsilateral ovary and between cows with high and low serum $\mathrm{P} 4$ level. Despite endometrial cytology is considered to be the accurate method to diagnose SE, histopathological examination is more reliable diagnostic method for SE. Future investigations should be done, to improved cut-off values for cytological examination for the diagnosis of SE in cows more than 60 days postpartum.

\section{Acknowledgments}

We acknowledge the ERAF project No. 1.1.1.1/16/A/025 'Preservation of bovine genetic resources in Latvia using embryo transfer and related biotechnologies’ for study`s financial support.

\section{References}

Benbia, S., Yahia, M., Letron, I.R., \& Benounne, O. (2017). Endometrial cells morphology depending on estrous cycle and histologic layers in cows: morphometric study. Global Veterinaria 18(1), 68-73. DOI: 10.5829/ idosi.gv.2017.68.73.

Cheong, S.H., Nydam, D.V., Galvao, K.N., Crosier, B.M., \& Gilbert, R.O. (2011). Cow-level and herd-level risk factors for subclinical endometritis in lactating Holstein cows. J Dairy Sci 94(2), 762-70. DOI: 10.3168/ jds.2010-3439.

Dogan, I., Sonmez, G., \& Sagirkaya, H. (2002). Histopathological investigation of endometrium in repeat breeder cows. Indian Journal of Animal Sciences 72(3), 223-226. Retrieved March 17, 2020, from https:// www.researchgate.net/publication/297910246.

Espejel, M.C., \& Medrano, A. (2017). Histological cyclic endometrial changes in dairy cows: An Overview. Dairy and Vet Sci J 2(1), 555577. DOI: 10.19080/JDVS.2017.02.555577.

Estrada-Cortés, E., Ortiz, W.G., Chebel, R.C., Jannaman, E.A., Moss, J.I., Cavallari de Castro, F., Zolini, A. M., Staples, C.R., \& Hansen, P.J. (2019). Embryo and cow factors affecting pregnancy per embryo transfer for multiple-service, lactating Holstein recipients. Translational Animal Science 3(1), 60-65. DOI: 10.1093/tas/txz009.

Egberts, J., Detterer, J., Park, A., \& Meinecke-Tillmann, S. (2016). Exfoliative endometrial cytology in embryo donor cows - comparison of sampling localizations for the diagnosis of subclinical endometritis. Veterinary Sciences 3(4), 35. DOI: 10.3390/vetsci3040035.

Gilbert, R.O., Shin, S.T., Guard, C.L., Erb, H.N., \& Frajblat, M. (2005). Prevalence of endometritis and its effects on reproductive performance of dairy cows. Theriogenology.64(9), 1879-88. DOI: 10.1016/j. theriogenology.2005.04.022. 
Jimenez-Krassel, F., Folger, J.K., Ireland, J.L.H., Smith, G.W., Hou, X., Davis, J.S., Lonergan, P., Evans, A. C.O., \& Ireland, J.J. (2009). Evidence that high variation in ovarian reserves of healthy young adults has a negative impact on the corpus luteum and endometrium during estrous cycles in cattle. Biology of Reproduction 80 (6), 1272-1281. DOI: 10.1095/biolreprod.108.075093.

Kasimanickam, R., Duffield, T.F., Foster, R.A., Gartley, C.J., Leslie, K.E., Walton, J.S., \& Johnson, W.H. (2004). Endometrial cytology and ultrasonography for the detection of subclinical endometritis in postpartum dairy cows. Theriogenology 62(1-2), 9-23. DOI: 10.1016/j.theriogenology.2003.03.001.

Madoz, L.V., Giuliodori, M.J., Jaureguiberry, M., Plontzke, J., Drillich, M., \& de la Sota, R.L. (2013). The relationship between endometrial cytology during estrous cycle and cutoff points for the diagnosis of subclinical endometritis in grazing dairy cows. Journal of Dairy Science 96(7), 4333-4339. DOI: 10.3168/ jds.2012-6269.

Melcher, Y., Prunner, I., \& Drillich, M. (2014). Degree of variation and reproducibility of different methods for the diagnosis of subclinical endometritis. Theriogenology 82(1), 57-63. DOI: 10.1016/j. theriogenology.2014.03.003.

Muira, R. (2019). Physiological characteristics and effects on fertility of the first follicular wave dominant follicle in cattle. Journal of Reproduction and Development 65(4), 289-295. DOI: 10.1262/jrd.2019-027.

Pascottini, O.B., Hostens, M., Dini, P., Vandepitte, J., Ducatelle, R., \& Opsomer, G. (2016). Comparison between cytology and histopathology to evaluate subclinical endometritis in dairy cows. Theriogenology, 86(6), 1550-1556. DOI: 10.1016/j.theriogenology.2016.05.014.

Pascottini, O.B., Hostens, M., Sys. P., Vercauteren, P., \& Opsomer, G. (2017). Risk factors associated with cytologycal endometritis diagnosed at artificial insemination in dairy cows. Theriogenology 92, 1-5. DOI: 10.1016/j.theriogenology.2017.01.004.

Pothmann, H., Prunner, I., Wagener, K., Jaureguiberry, M., de la Sota, R., L., Erber, R., Aurich, C., EhlingSchulz, M., \& Drillich, M. (2015). The prevalence of subclinical endometritis and intrauterine infections in repeat breeder cows. Theriogenology 83(8), 1249-1253. DOI: 10.1016/j.theriogenology.2015.01.013.

Sánchez, J.M., Passaro, C., Forde, N., Browne, J.A., Behura, S.K., Fernández-Fuertes, B., Mathew, D.J., Kelly, A.K., Butler, S.T., Spencer, T.E., \& Lonergan, P. (2018). Do differences in the endometrial transcriptome between uterine horns ipsilateral and contralateral to the corpus luteum influence conceptus growth to day 14 in cattle? Biology of Reproduction. 100(1), 86-100. DOI: 10.1093/biolre/ioy 185.

Wagener, K., Gabler, C., \& Drillich, M. (2017). A review of the ongoing discussion about definition, diagnosis and pathomechanism of subclinical endometritis in dairy caws. Theriogenology 94, 21-30. DOI: 10.1016/j. theriogenology.2017.02.005.

Wang, C.K., Robinson, R.S., Flint, A.P.F., \& Mann, G.E. (2007). Quantitative analysis of changes in endometrial gland morphology during the bovine oestrous cycle and their association with progesterone levels. Reproduction 134(2), 365-371. DOI: 10.1530/REP-06-0133. 